\title{
Reply \\ to the Letter of Eleftheriadis et al.
}

\author{
Shih-Ping Hsu ${ }^{a, b, c}$ Chih-Kang Chiang ${ }^{a, b}$ Chiang-Ting Chienc Kuan-Yu Hung ${ }^{a, b}$ \\ ${ }^{\mathrm{a}}$ Department of Internal Medicine, Far Eastern Memorial Hospital, and Departments of ${ }^{\mathrm{b}}$ Internal Medicine and \\ ${ }^{c}$ Clinical Research, National Taiwan University Hospital, Taipei, Taiwan
}

Sir,

We are pleased to know that not only our group [1], but also other teams are interested in studying the relationships between plasma hepcidin (prohepcidin) levels and anemia in hemodialysis (HD) patients $[2,3]$. However, there are apparently some discrepancies in the findings and interpretations among the studies.

Eleftheriadis et al. [2] stated they found that serum prohepcidin levels were negatively correlated with hematocrit (Hct) in their HD patients, compatible with the findings reported by Małyszko et al. [3]. Furthermore, they concluded that prohepcidin was the major and negative determinant of Hct. On the other hand, our group has found a positive correlation between plasma prohepcidin levels and Hct, suggesting prohepcidin expression might be positively regulated by Hct [1]. Kulaksiz et al. [4] have also found that dialysis patients without renal anemia have higher levels of plasma prohepcidin than those in the patients with renal anemia.

Indeed, many studies have proposed that hepcidin inhibits intestinal iron absorption and iron release from macrophages, and causes anemia of chronic disease (ACD) with low transferrin saturations and high ferritin levels. However, it would not be the case in renal anemia. Compatible with the findings reported by
Eleftheriadis et al. [2], we failed to find any significant correlation between plasma prohepcidin levels and iron profiles in HD patients. The possible explanations have been stated in our article [1]. Moreover, Nicolas et al. [5] reported in their experimental study that anemia suppresses the expression of hepcidin, indicating that low Hct would suppress the expression of prohepcidin in a feedback manner. Therefore, it is reasonable that there is a positive correlation between Hct and prohepcidin levels in HD patients.

We agree the major limitation in studying the role of hepcidin in renal anemia in HD patients is the lack of a feasible, clinical method to detect plasma levels of hepcidin rather than prohepcidin. Before further conclusive results can be proposed concerning the relationship between plasma hepcidin (prohepcidin) levels and anemia in HD patients, it is mandatory to first clarify the relationship between plasma hepcidin and prohepcidin levels in HD patients.

\section{References}

1 Hsu SP, Chiang CK, Chien CT, Hung KY: Plasma prohepcidin positively correlates with hematocrit in chronic hemodialysis patients. Blood Purif 2006;24:311-316.
2 Eleftheriadis T, Liakopoulos V, Kartsios C, Antoniadi A, Atmatzidis E, Anifandis G, Oikonomidou E, Markala D, Stefanidis I: Does hepcidin affect erythropoiesis in hemodialysis patients? XLIII ERA-EDTA Congress, Glasgow, 2006, SP431.

3 Małyszko J, Małyszko JS, Hryszko T, Pawlak $\mathrm{K}$, Mysliwiec M: Is hepcidin a link between anemia, inflammation and liver function in hemodialyzed patients? Am J Nephrol 2005; 25:586-590.

4 Kulaksiz H, Gehrke SG, Janetzko A, Rost D, Bruckner T, Kallinowski B, Stremmel W: Pro-hepcidin: expression and cell specific localisation in the liver and its regulation in hereditary haemochromatosis, chronic renal insufficiency, and renal anemia. Gut 2004; 53:735-743.

5 Nicolas G, Chauvet C, Viatte L, Danan JL, Bigard X, Devaux I, Beaumont C, Kahn A, Vaulont $\mathrm{S}$ : The gene encoding the iron regulatory peptide hepcidin is regulated by anemia, hypoxia, and inflammation. J Clin Invest 2002;110:1037-1044.

Shih-Ping Hsu, MD

Department of Internal Medicine

Far Eastern Memorial Hospital, No. 21, Sec. 2

Nan-Ya South Road, Pan-Chiao

Taipei (Taiwan)

Tel. +886289667000 , ext. 1164

Fax +886289665567

E-Mail shihping99@sina.com.tw 